\title{
Mesoscopic surface roughness of ice crystals pervasive across a wide range of ice crystal conditions
}

\author{
N. B. Magee, A. Miller, M. Amaral, and A. Cumiskey \\ The College of New Jersey, Ewing, NJ, USA \\ Correspondence to: N. B. Magee (magee@tcnj.com)
}

Received: 19 December 2013 - Published in Atmos. Chem. Phys. Discuss.: 28 March 2014

Revised: 23 September 2014 - Accepted: 10 October 2014 - Published: 25 November 2014

\begin{abstract}
Here we show high-magnification images of hexagonal ice crystals acquired by environmental scanning electron microscopy (ESEM). Most ice crystals were grown and sublimated in the water vapor environment of an FEIQuanta-200 ESEM, but crystals grown in a laboratory diffusion chamber were also transferred intact and imaged via ESEM. All of these images display prominent mesoscopic topography including linear striations, ridges, islands, steps, peaks, pits, and crevasses; the roughness is not observed to be confined to prism facets. The observations represent the most highly magnified images of ice surfaces yet reported and expand the range of conditions in which rough surface features are known to be conspicuous. Microscale surface topography is seen to be ubiquitously present at temperatures ranging from $-10^{\circ} \mathrm{C}$ to $-40^{\circ} \mathrm{C}$, in supersaturated and subsaturated conditions, on all crystal facets, and irrespective of substrate. Despite the constant presence of surface roughness, the patterns of roughness are observed to be dramatically different between growing and sublimating crystals, and transferred crystals also display qualitatively different patterns of roughness. Crystals are also demonstrated to sometimes exhibit inhibited growth in moderately supersaturated conditions following exposure to near-equilibrium conditions, a phenomenon interpreted as evidence of 2-D nucleation. New knowledge about the characteristics of these features could affect the fundamental understanding of ice surfaces and their physical parameterization in the context of satellite retrievals and cloud modeling. Links to supplemental videos of ice growth and sublimation are provided.
\end{abstract}

\section{Introduction}

It has been broadly recognized (IPCC, 2007; Bony et al., 2006) that cloud-climate feedbacks are the most weakly constrained radiative forcings for general circulation models of a changing future climate. Among the variety of cloud feedbacks that have been identified and parameterized, cirrus clouds are notable for being especially uncertain - even the sign (positive or negative) of the likely feedback effect is subject to debate (Mitchell et al., 2008; Burkhardt, 2011). Baran (2012) presents a compelling case that the complex radiative scattering properties of heteromorphic ice crystals must be accounted for to reach a physically consistent parameterization of ice clouds in climate models. In addition to cloud-climate feedbacks, it is expected that prominent mesoscopic topography (defined here as variation scale between $100 \mathrm{~nm}$ and $5 \mu \mathrm{m}$ ) would affect active research questions in stratospheric ozone chemistry (McNeill et al., 2007) and thunderstorm electrification (Dash et al., 2001). Despite recognition that the microscale structures of ice are critically important to consider, very few images of ice are available at this resolution.

While many experimental research efforts have characterized the effects of temperature, supersaturation, and pressure on particle-scale ice crystal growth rates and morphology under conditions relevant to atmospheric processes (Lamb and Hobbs 1971; Kuroda and Lacmann, 1982; Bailey and Hallett, 2004; Nelson and Knight, 1998; Magee et al., 2006), to date the limits of light microscopy have prevented a thorough analysis of the surface details of ice crystals beyond the microscale. Several studies have employed interference techniques or ellipsometry to suggest the presence of surface structure and disorder of ice (Bryant et al., 1960; Furukawa et al., 1987; Sazaki et al., 2010), but no highly resolved im- 
ages of mesoscopic surface structure have been available. Early SEM studies examined formvar replicas of ice crystals, and in some instances were successful in revealing crystal structures beyond the resolution of light microscopy (Shaefer, 1941; Truby, 1955; Kuroiwa, 1969; Goodman et al., 1989). The use of chemical etchants also revealed new information on the nature of lattice defects in ice and provide tantalizing images that are reminiscent of the some of the mesoscopic structures seen in the present work (Truby, 1955; Kuroiwa, 1969). Despite the availability of sub-micron details that can be preserved by proper application of formvar replication, several authors have pointed out that the effects of the solvents on the surface are hard to define (e.g., Takahashi, 1988). The first scanning electron micrographs of non-replicated ice were made from platinum sputter-coated natural snowflakes by Wergin et al. (1995); their striking images show a variety of complex structures, but due to warm collection conditions and the sputtering processes, they are ambiguous with respect to presence of mesoscopic surface structure (Wergin et al., 1995). Recently, Neshyba et al. (2013), Ulanowski et al. (2014), Petersen et al. (2011), Pfalzgraff et al. (2010), Kuhs et al. (2010), and Zimmerman et al. (2007) have used uncoated, in situ growth of ice crystals in environmental scanning electron microscopy (ESEM) or variable-pressure scanning electron microscopy (VPSEM) to identify surface roughness in the form of ridges or "trans-prismatic" strands. Through images resolved at up to $10000 \times$ magnification (compared with previous maximum magnifications of $\sim 1000 \times$ ), our observations underscore this newly emerging view of the ice surface, demonstrating that mesoscopic surface roughness is a non-uniform condition present on a wide array of ice crystals, and is not confined to a narrow range of macroscopic morphology, substrate, temperature, humidity, or growth rates.

Over 50 years have passed since the first account of a relationship between surface roughness and specular reflectivity (Bennett and Porteus, 1961). A growing recognition is now emerging that divergence away from the classical smoothfacet assumption for ice will affect understanding of how light is scattered. A broad suite of recent measurements and models describes the potential effect of surface roughness and complex microscale geometry in smoothing the peaks of the ice-scattering phase function (Baran, 2012; Baum et al., 2010, 2011; Cotton et al., 2010; Heymsfield et al., 2006; Ulanowski et al., 2006, 2010, 2012; Um and McFarquhar, 2011).

Despite acknowledged uncertainty regarding the details of real roughened ice surfaces, several recent studies have concluded that cirrus radiative measurements and models come into better agreement when attempting to account for complicated shapes and rough ice surfaces. For example, Kahnert et al. (2008) estimated that the effect of varying parameterizations of ice surface microphysics can affect the modeled radiative influence of cirrus by a factor of two. Baum et al. (2011) recently determined that assumption of a roughened ice surface results in better fits to ice particle data retrievals from the CALIOP (Cloud-Aerosol Lidar with Orthogonal Polarization) lidar instrument on board the NASA-CNES CALIPSO (Cloud-Aerosol Lidar and Infrared Pathfinder Satellite Observations) A-train satellite. Polarized ice-cloud reflectances have also been shown to have high sensitivity to ice particle geometry and texture (Chepfer et al., 2001; Baran and Labonnote, 2006). Polarized ice-cloud reflectances measured by the PARASOL (Polarization and Anisotropy of Reflectances for Atmospheric Sciences coupled with Observations from Lidar) satellite have been found to agree best with a mixed-habit model of severely roughened ice particles (Cole et al., 2013), and retrievals indicate the greatest average roughness in ice clouds associated with tropical deep convection (Cole et al., 2014). Mauno et al. also point out discrepancies between measured and modeled cirrus-modulated shortwave radiative fluxes that would be improved by assumption of surface roughness on ice crystals (Mauno, 2011). In addition to passive satellite measurements of cirrus ice microphysics, it is also likely that ice scattering functions assumed in radar and lidar imaging of cirrus and mixed-phase cloud properties would be affected (Sun et al., 2011). Because satellite observations, aircraft measurements, and modeling of cirrus and mixed-phase clouds have often been at odds (Baran, 2012; Garrett and Gerber, 2003; Gierens et al., 2003; Kramer et al., 2009; Harrington et al., 2009; Jensen et al., 2009; McFarquhar et al., 2007; Peter et al., 2006; Connolly et al., 2007), potential artifacts of surface roughness on both satellite retrievals and modeling of ice microphysics must be carefully evaluated.

\section{Methods}

We employed an FEI Quanta-200 field emission gun environmental scanning electron microscope (FEG ESEM) to observe ice crystals at temperatures from -10 to $-45^{\circ} \mathrm{C}$ and through a wide range of subsaturated, equilibrium, and supersaturated vapor pressures. Most of our experiments examined in situ nucleation, growth, and sublimation of ice crystals in the pure water vapor environment of the ESEM. Several experiments also included imaging of ice crystals grown in an external diffusion chamber and then transferred into the ESEM.

\subsection{In situ growth and sublimation}

In situ growth and sublimation experiments were conducted on the ESEM stage, with the ice nucleating on a substrate mounted to a Peltier cooling block. An aluminum stub fitted to the Peltier block was machined to expose a $1 \mathrm{~mm}$ diameter surface to the chamber environment such that the entire surface could be contained in the ESEM field of view at low magnification. An insulating vinyl mask was used to ensure that ice growth was limited to the intended cold sur- 
face. Growth and sublimation experiments were conducted on bare aluminum as well as on a variety of thin substrates that were attached to the aluminum by thermally conductive epoxy. Substrates that were tested included stainless steel, aluminum, and copper, as well as mineral substrates including covellite, muscovite, bismuth, magnesite, galena, and quartz.

Once the substrate was mounted onto the Peltier stage, the ambient air in the ESEM chamber was evacuated and backfilled with water vapor, after which the ice growth experiments were initiated. After cooling to a temperature at or above $-45^{\circ} \mathrm{C}$, ice nucleation, growth, and sublimation was controlled through direct adjustment of the water vapor pressure or surface temperature. Vapor pressure was controlled at $0.5 \mathrm{~Pa}$ increments between 0 and $500 \mathrm{~Pa}$ via automatic differential pumping. Vapor measurements were made to $0.1 \mathrm{~Pa}$ resolution. In a typical experiment, vapor pressure was first adjusted to the equilibrium frost point and subsequently increased in small increments until ice crystal nucleation was observed. A magnification of $100 \times$ was employed until ice crystal growth became visible, after which variable resolutions (as high as $\sim 10000 \times$ ) were used to capture detailed images and videos of the growing ice crystals. Maximum image acquisition size for the FEI Quanta 200 is $4096 \times 3775$ pixels $(\sim 15.5 \mathrm{MP})$. At $2500 \times$ magnification, this results in each pixel having dimensions $25.4 \mathrm{~nm} \times 25.4 \mathrm{~nm}$. At this magnification, we observed that typical imaging conditions resulted in linear features that could be resolved at limits of 2-3 pixels $(50-75 \mathrm{~nm})$. With increasing magnification, signal-to-noise reduction partially (but not completely) offset resolution gains, such that we estimate a resolution limit of approximately $25 \mathrm{~nm}$ for these methods.

In a typical experiment, the differential pumping and thermoelectric cooling of the substrate required approximately $10 \mathrm{~min}$ to reach equilibrium values of vapor pressure near $65 \mathrm{~Pa}$ and $-25^{\circ} \mathrm{C}$. Temperature of the Peltier block is automatically reported through the FEI instrument software to $0.1^{\circ} \mathrm{C}$ resolution and the water vapor pressure is reported to $0.1 \mathrm{~Pa}$ resolution. Based upon drop freezing measurements and trials of substrate-free growth, we are confident that vapor pressure values were precisely and accurately controlled and reported; however, we determined that the surface temperature of the substrate was typically several degrees warmer $\left(+0.5\right.$ to $\left.+6.5^{\circ} \mathrm{C}\right)$ than the temperature indicated for the Peltier base. This offset was determined by observing the (equilibrium) vapor pressure at which ice neither grew nor sublimated and inferring surface temperature from the Murphy and Koop vapor pressure formulation (2005); we observed this thermal offset to vary based on the temperature, the thickness of the substrate, and its thermal conductivity. Additional detail for the calibration of temperature offset and calculated saturation ratio is provided in Appendix A. Following the approach to equilibrium, vapor pressure was raised in $0.5 \mathrm{~Pa}$ increments until nucleation of one or several ice crystals occurred. It was frequently challenging to nucleate a single crystal, even with incremental increases in vapor pressure. Once a crystal of interest was developed, it was examined and photographed at a variety of magnifications, ranging from $100 \times$ to $10000 \times$, at a variety of vapor densities, including super- and subsaturated conditions, and through multiple cycles of growth and sublimation.

\subsection{Transported crystals}

In order to image crystals grown in the presence of background air pressure and to minimize the role of the growth substrate, we also developed a new technique to grow, capture, and transfer ice crystals from a controlled diffusion chamber into the ESEM. Ice crystals were grown in a diffusion chamber contained within a large-volume, ultra-low temperature freezer. In this procedure, the full freezer volume is held at $-55^{\circ} \mathrm{C}$ and all walls are coated with ice to achieve a saturated environment. The diffusion chamber generates a small region of supersaturation along a thin vertical fiber between two parallel, horizontal ice plates, with the ice surface temperatures maintained by thermoelectric modules. Ice crystals were grown at ambient lab pressure $(\sim 1000 \mathrm{hPa})$ and at low supersaturation $\left(<110 \% \mathrm{RH}_{i}\right)$, with temperature near $-50^{\circ} \mathrm{C}$, usually with many crystals in close proximity along the fiber. Within the saturated freezer, several dozen of these ice crystals were then captured in a prechilled small-volume $\left(\sim 1 \mathrm{~cm}^{3}\right)$ containment cell. The transfer and sealing process from diffusion chamber to cryo-cell requires just a few seconds, and intentionally avoids any exposure to ambient room air. The base of the containment cell was formed from an aluminum stub to allow direct transfer into the ESEM cooling stage. Upon capture, the cell was sealed closed and transferred to a specially designed cryogenic dewer (filled with liquid nitrogen or crushed dry ice) for transport to the ESEM. The cell was then removed from the dewer and quickly placed onto the pre-chilled cooling stage of the ESEM. Throughout the capture and transfer process, the primary objective was to allow ESEM imaging of the ice surfaces as they had been growing in the diffusion chamber and without additional sublimation or growth. To prevent unintended sublimation, the small-volume containment cell was filled with many crystals and quickly sealed so that equilibrium vapor pressures would preserve the crystal surfaces. The containment cell was also enveloped by materials with significant heat capacity and the cryo-dewer designed and handled to maintain near isothermal conditions. Once the sealed containment cell was transferred to the ESEM cooling stage, the microscope chamber was evacuated and adjusted to equilibrium vapor pressures matching the cold stage and containment cell temperature. After reaching equilibrium vapor pressure in the ESEM chamber, the containment cell was then opened using electronically driven stage movement to mechanically pull off the top seal. Following unsealing of the containment cell, ESEM imaging 
could proceed as in the in situ growth and sublimation experiments.

\section{Results and discussion}

The overriding impression from our experiments suggests that surface structures on the 0.1 to 10 micron scale are a ubiquitous feature of ice crystal facets. The morphologies of many of these structures agree with observations recently reported by Neshyba et al. (2013), Ulanowski et al. (2014), Pfalzgraff et al. (2010), Petersen et al. (2011), and Zimmerman et al. (2007). Our observations provide new evidence of roughening on basal crystal facets, as well as images and videos at high magnifications $(1000 \times$ to $10000 \times)$ that reveal smaller-scale roughening not readily apparent at magnifications below $1000 \times$. Our observations also show strongly differing morphology between textures of growing surfaces and those of sublimating surfaces. The results also include images of ice crystals grown in air-vapor mixtures and then transferred into the ESEM. These images do show mesoscopic surface roughness, but suggest that the presence of air or different modes of internal heat transfer may significantly affect the character of surface texture development.

\subsection{Growing crystals}

As described in Sect. 2.1, ice crystals where nucleated and grown on an ESEM cold state at a variety of temperatures and pressures. Crystals typically nucleated at just a few percent above equilibrium vapor pressures and continued to grow steadily in proportion to the magnitude of ice supersaturation. At high supersaturations ( $\left.>150 \% \mathrm{RH}_{i}\right)$, nucleation and growth proceeded so quickly that it was difficult to isolate and follow the progression of a single crystal, as the entire stage would be overtaken by intersecting crystals within a few seconds. Therefore, most growth experiments were conducted at modest supersaturation, usually $105-125 \% \mathrm{RH}_{i}$. While we did observe clear surface morphology differences between growing and sublimating crystals, we did not detect a systematic dependence on the degree of supersaturation, the rate of growth, or the composition of the underlying substrate.

\subsubsection{Roughness morphologies and scales}

In our ESEM growth experiments, we observed mesoscopic linear striations on prism faces (Fig. 1e-g) similar to those described by Neshyba et al. (2013) and Pfalzgraff et al. (2010) as well as a variety of other mesoscopic roughness structures. Figure 1 provides a multi-panel view of characteristic growing surface features across the range of our roughness observations. The panels are organized with temperature decreasing toward the bottom and magnification increasing toward the right of the figure. The magnification, tempera- ture, pressure, and humidity information from the data bars are available for easier viewing in the Appendix Table A1.

Particularly in Fig. 1a, c, d, f, and g, distinct roughness can be observed on the basal facets of growing crystals as well as the prism facets. The basal plane roughness usually appears less linear and less symmetrically organized than the prismatic strands. Image sequences (typically spaced at $\sim$ $1 \mathrm{frame} / \mathrm{s}$ ) reveal the dynamic progress of roughening features as they migrate across the ice surface (videos available in supplemental data, see especially BasalRoughnessLayers.mp4 and SingleCrystal.mp4). Figure 1g-i also display evidence of microfaceting on basal and prism facets. Microfaceting could be induced by cycles of growth and sublimation at all temperatures, but was only observed to develop during steady growth at temperatures below $-35^{\circ} \mathrm{C}$.

These data have also confirmed the idea that surface roughness can be enhanced in proximity to a grain boundary between two neighboring crystals (e.g., Pedersen et al., 2011). In Fig. 1b, it is apparent that the ridges (in the center of the image) become larger just as the two advancing facets collide, with ridges radiating outward from the impact point. A video of ridge topographic intensification precipitated by colliding ice crystals is available in the supplementary material (ImpactWave.mp4). It is possible that this effect might enhance roughness in aggregates of ice particles or in cloud regions with high collision frequencies, both of which have been found to be particularly common near deep convection regions, which have also been associated with satellite retrievals indicative of severe particle roughening (Cole et al., 2014). Blackford (2007) and Pedersen et al. (2011) also point out that the microstructure of ice along grain boundaries can play an important role in advancing the understanding of the mechanical properties of snowpacks that are susceptible to avalanche, as well as the dynamics of glaciers.

\subsubsection{Magnification and contrast effects}

Figure 2 shows a four-panel plot of a growing hexagonal ice crystal starting at $762 \times$ magnification in Fig. 2a. This crystal was grown near $-21^{\circ} \mathrm{C}$ and is being held near equilibrium in this sequence of panels; the crystal was not visibly growing or sublimating across the $57 \mathrm{~s}$ separating the first and final panels. Mesoscopic topography is not visible in Fig. 2a, so the magnification was increased to $2155 \times$ (Fig. 2b), which made roughness apparent on the prism facets of the ice crystals. However, we could not see whether any complex surface architecture existed on the basal facet, since it is tilted almost perpendicular to our viewing angle. By increasing the magnification further and adjusting the contrast and brightness of the ESEM, Fig. 2c shows that rough surface topography was actually present on the basal facet (at $3625 \times$ magnification). A measurement was made of the depth of a prominent terrace in Fig. $2 d$ (1.59 microns, again at $3625 \times$ magnification); this terrace is among the thickest observed during experiments, suggesting that most topographic features have heights well 


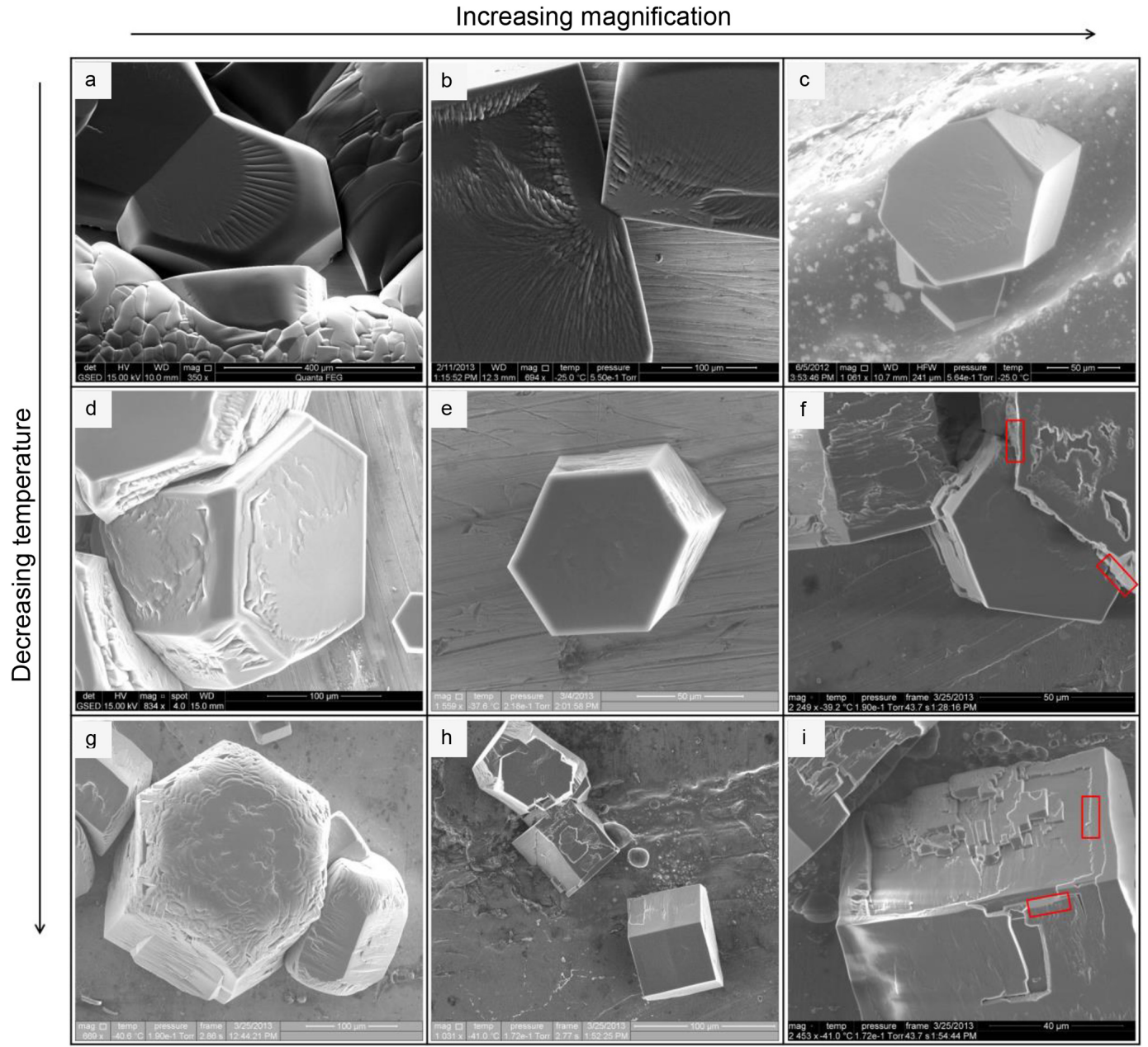

Figure 1. Image panels at a variety of magnification, temperatures, and pressures, all showing various examples of mesoscopic surface topography. Red rectangles in panels (f) and (i) show sites used for calculating roughness measure $<r>$. Data detail available in Appendix Table A1.

below 1 micron. This pattern was typical of all experiments; only the most prominent surface structures were typically visible at a magnification of $500 \times-1000 \times$, while closer examination at $1000-5000 \times$ would reveal smaller-scale structures and topography that had not been resolved at lower magnification, or at sub-optimal aspect, brightness, and/or contrast.

We attempted to extract profiles of surface height from our ESEM micrographs in to calculate the roughness measure $<r>$ recently defined by Neshyba et al. (2013) in the context of carefully measured mesoscopic striations observed on ice prism facets growing in VPSEM at $-45^{\circ} \mathrm{C}$ :

$r=1-\sqrt{\frac{1}{1+\left(\frac{\mathrm{d} y}{\mathrm{~d} z}\right)^{2}}}$.

The average roughness $\langle r\rangle$ is determined along the measured profile. In several circumstances, we succeeded in retrieving an approximate profile, but, as indicated by
Ulanowski et al. (2014), in most routine SEM imaging circumstances, we found that it was not straightforward to extract this height profile with confidence. Where this profile could be estimating on growing crystals imaged at magnifications similar to those analyzed by Neshyba et al. 2013 $(\sim 300-500 \times$ magnification), we retrieved similar values of roughness near $\langle r\rangle \approx 0.05$. Height profiles along several sections of more highly magnified crystals indicated by red rectangles in Fig. If and i yielded $\langle r\rangle$ between 0.10 and 0.40 . Height profiles, and thereby $<r>$ values, can be retrieved by careful attention during the imaging process to SEM stage and crystallographic orientation, resolving of crystal edges, or potentially by $3-D$ reconstruction of equilibrium crystals captured from multiple angles. We found that it was usually not possible to determine height profiles when structures, although visible, are near the limit of the image resolution, or where pronounced roughness did not intersect a resolved crystal edge, a common feature in our observa- 


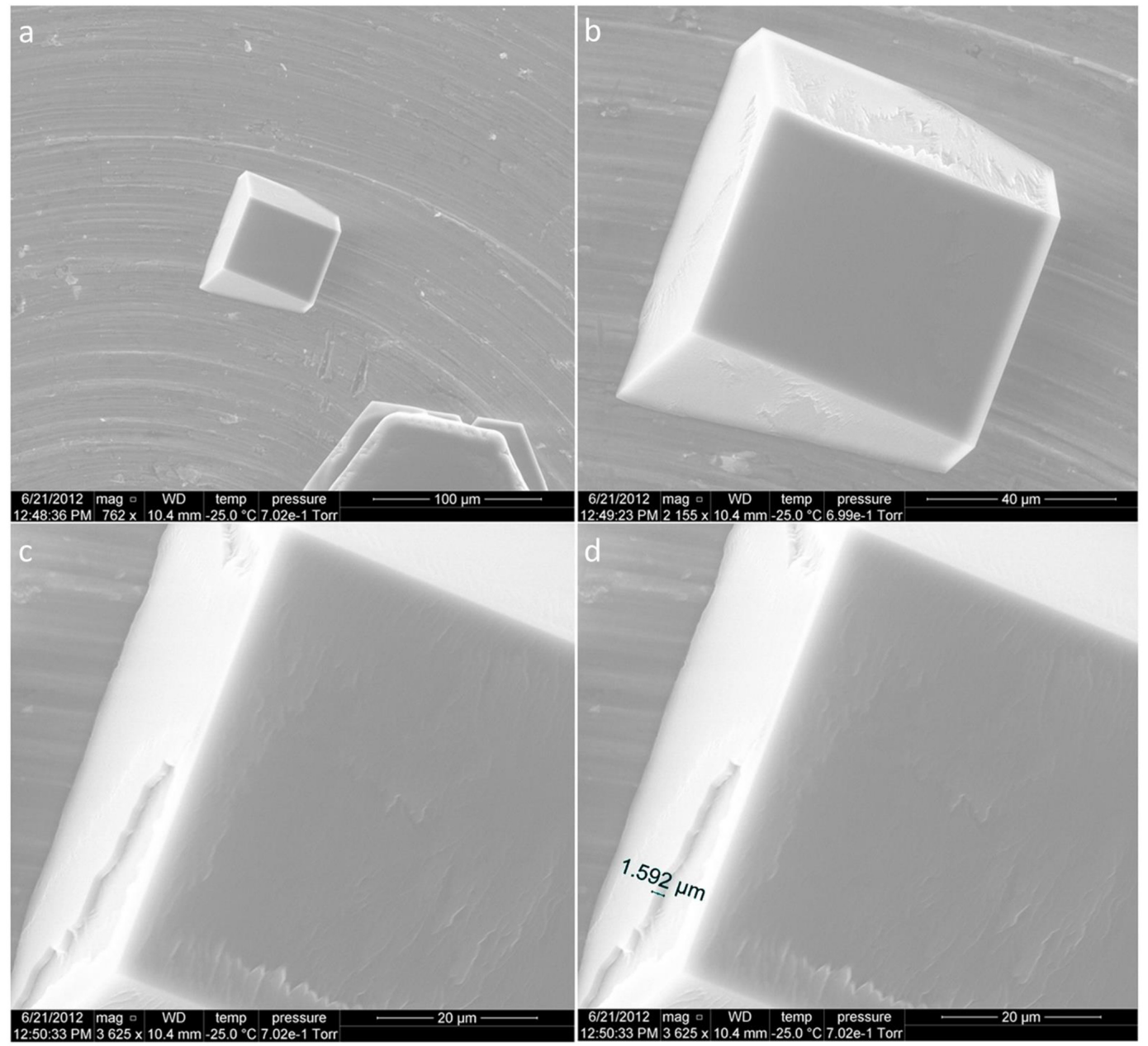

Figure 2. Demonstration of increased magnification effect upon perceived roughness, as well as a measurement of ridge depth (panel d). Data detail available in Appendix Table A1.

tions. We also find that the $<r>$ metric, much like the subjective perception of roughness, is affected by image magnification and resolution, and in turn by the minimum sampling interval of the height profile. If, as our observations imply, surface roughness is significant at sub-micron scales that are not well resolved at $500 \times$ magnification, $\langle r>$ values obtained from profiles retrieved at $500 \times$ may be underestimating total roughness.

\subsubsection{Inhibited growth observations}

As expected with growth experiments conducted on large, rough substrates, we observed that most crystals nucleated at low supersaturation and then grew steadily and at a rate proportional to ice supersaturation values. At temperatures below $-30^{\circ} \mathrm{C}$, we repeatedly observed crystals where growth became completely stalled, even at moderate supersaturations $\left(>115 \% \mathrm{RH}_{i}\right)$ that had previously induced growth in that crystal and continued to lead to growth in adjacent crystals. This stalled growth was only observed following a spe- cific cycle of humidity adjustment: the excess vapor supply of a steadily growing crystal was gradually reduced until reaching equilibrium, with observable growth ceasing, and with no sublimation apparent. This equilibrium condition was held for $1-5 \mathrm{~min}$, after which the vapor pressure was gradually increased (or temperature decreased) until $\mathrm{RH}_{i}$ exceeded equilibrium by a few percent. In many instances, the original crystal would not resume growth, even though adjacent crystals continued to nucleate and grow. Figure 3 provides time-separated panels illustrating one such event in which a crystal previously held at equilibrium failed to grow following a $0.3^{\circ} \mathrm{C}$ decrease in temperature, despite several nearby crystals nucleating and growing (see supplemental videos Inhibited1.mp4, Inhibited2.mp4, and Inhibited3.mp4 for additional examples). We interpret this an example of side-by-side ice crystals subject to two different surface conditions: (a) steady growth continues at emergent dislocations or stacking faults, likely partly induced by the underlying substrate and (b) a previously rough surface has been recon- 


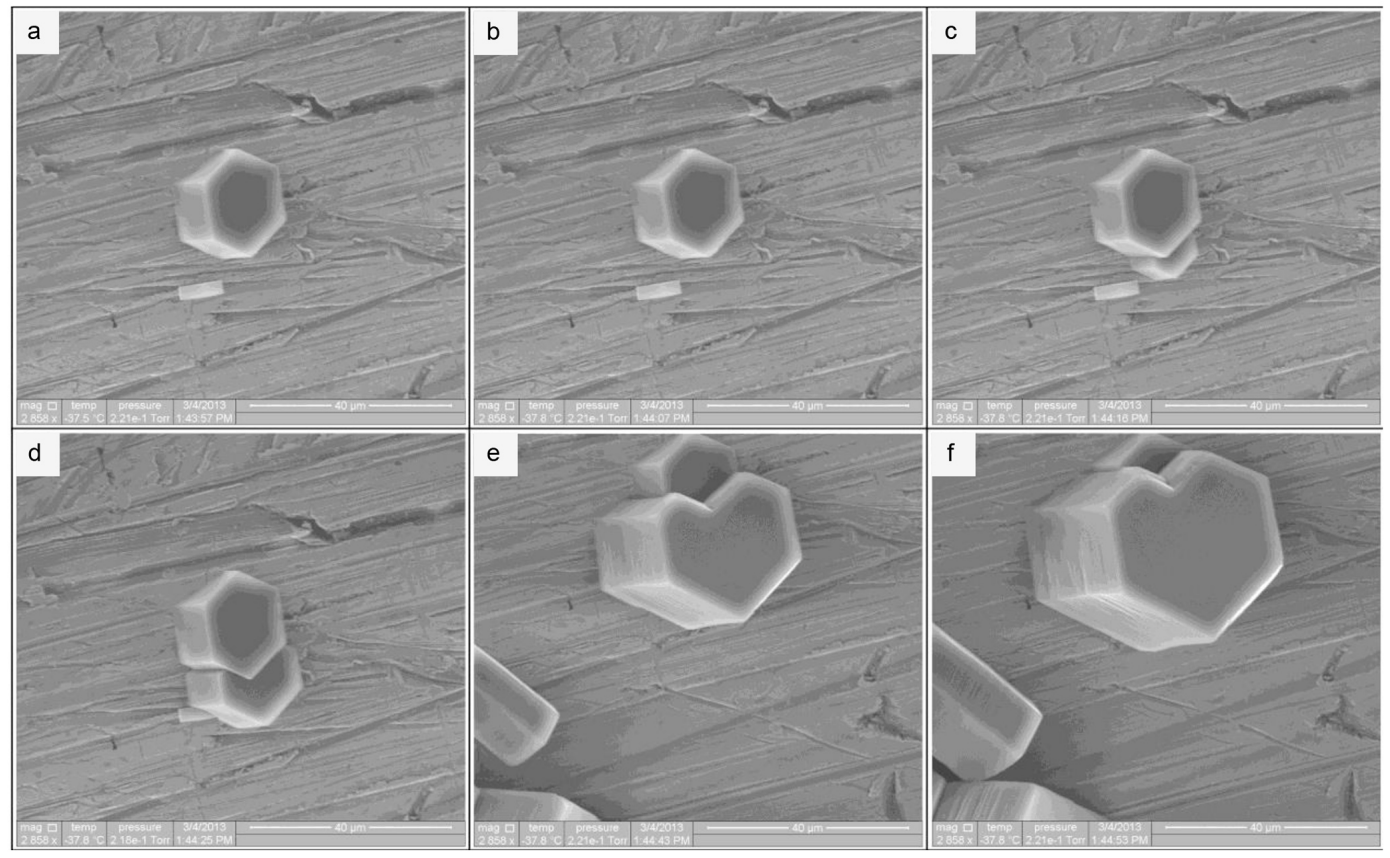

Figure 3. Series of frames separated by $\sim 10 \mathrm{~s}(20 \mathrm{~s}$ between panels (d) and (e) as the acquisition was re-centered to capture growing crystals at bottom left in these panels). The original two crystals at equilibrium in panel (a) do not grow when subjected to a temperature decrease of $0.3{ }^{\circ} \mathrm{C}$ (equivalent to $\sim 105 \mathrm{RH}_{i}$ ), with vapor pressure held constant. Data detail available in Appendix Table A1.

ditioned by the momentary maintenance of equilibrium vapor pressure, leaving the surface to grow only by 2-D nucleation requiring vapor in excess of a critical supersaturation. The stalled crystal surfaces do not appear to be completely absent of mesoscopic roughness, nor are they observably different than the growing surfaces, implying that the surface condition differentiating separate growth mechanisms is determined at a smaller scale than observable here. The observation of growth at dislocations and 2-D nucleations would not be unprecedented: Sazaki et al. (2010) used interferencecontrast microscopy to demonstrate depositional growth in ice via both 2-D layer nucleation and spiral growth steps at screw dislocations. Several recent studies have also suggested that ice at temperatures below $-30^{\circ} \mathrm{C}$ does not have a well ordered hexagonal crystal structure. Instead, ice can contain a mixture of cubic and hexagonal sequences which can give rise to roughness on the prismatic faces (Malkin et al., 2012; Kuhs et al., 2012). It has also been shown that the proportion of cubic sequences decreases as ice is heated and the ice tends towards perfect hexagonal ice (Murray and Bertram, 2006; Kuhs et al., 2012). Both of these findings are consistent with the steady growth we observe at low supersaturation as well as the occurrence of inhibited growth when the surface is given the opportunity to anneal emergent stacking faults.

\subsection{Sublimating crystals}

In many instances, cycling of vapor pressure was conducted to observe the sensitivity of surface topography to ambient humidity. In the portions of the cycle below equilibrium vapor pressure, a significantly different character to the surface roughness was observed. Instead of regular or spreading ridges, plateaus, and steps, we observed concave, scalloped depressions developing away from the original surface. In the case of polycrystalline examples (Fig. 4a), the scalloped depressions took on especially dramatic shapes near former grain boundaries, with sharp peaks often evident during advanced sublimation. However, even single-crystal examples produced marked scalloping (Fig. 4b-d), which often initiated at the site of roughness produced during previous growth (see supplemental video GrowandSublime.mp4). It appears that the sublimation occurs outward from multiple centers, often at the site of a former ridge or ledge. In fact, on the basal plane, the sublimation can even be seen to produce hexagonal pits (visible in GrowandSublime.mp4 at $\sim 14 \mathrm{~s}$ ) and the scalloping develops partly from the intersection of multiple spreading pits. Furthermore, if the supersaturation was once again increased above equilibrium, the crystal would typically exhibit micro-faceting that initiated along the sharp ridges bounding adjacent sublimation scallops. The scale of the scalloping can become fairly large (e.g., Fig. 4a), so it would be surprising for these structures not to be seen by optical microscopy if they were indeed characteristic of sublimation in diffusion-limited regimes; we speculate that 

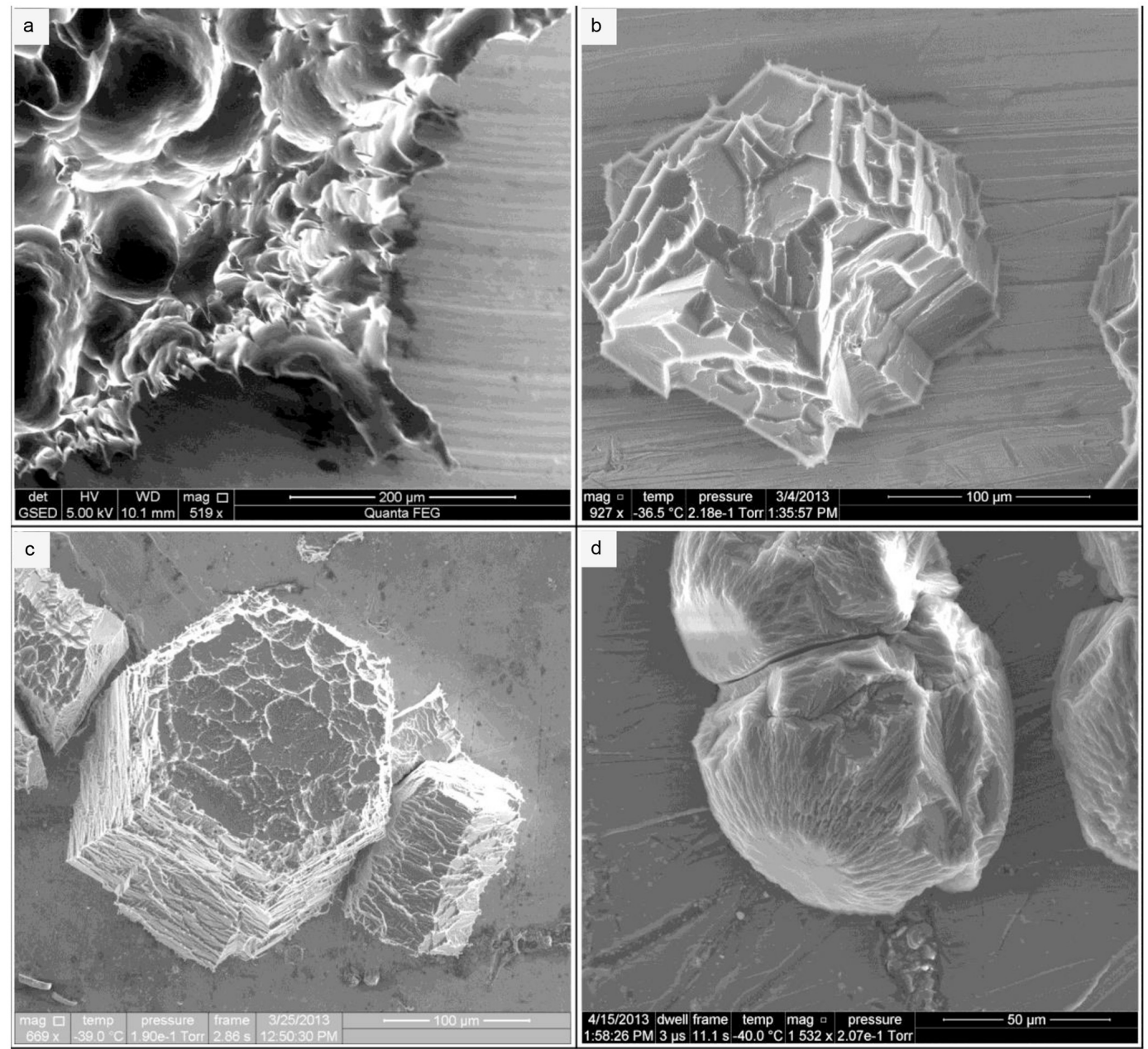

Figure 4. Sublimating ice crystals displaying scalloped depressions and sharp ridges and peaks of roughness. Panel (a) was originally composed of a polycrystalline ice particle, with peaks and ridges prominent at former grain boundaries. Data detail available in Appendix Table A1.

this mode of sublimation may be unique to the kinetic attachment regime, and perhaps significant only for very small ice atmospheric ice particles.

\subsection{Transported crystals}

As described in Sect. 2.2, ice crystals were grown at low supersaturation, at $-50^{\circ} \mathrm{C}$, and at ambient lab pressure in an external, freezer-based diffusion chamber and subsequently captured and transported to the ESEM cold stage in a sealed small-volume cell, with conditions maintained at ice/vapor equilibrium until imaging could commence. The goal of these experiments was to compare the character of surface roughness observed in experiments described in Sects. 3.1 and 3.2 with ice crystals grown in conditions more closely approximating cirrus clouds. While not completely isolated like an ice crystal floating in air, the crystals grown in the freezer chamber grew outward from a fiber, differentiating them from the close substrate contact seen with ESEM- grown crystals. The presence of large partial pressures of nitrogen and oxygen provides the other important departure from ESEM-grown crystals. It is important to note that crystals grown within the chamber (Figs. 1-5) are firmly within the attachment kinetics growth regime due to the absence of air and therefore low resistance to diffusion. By contrast, the transported crystals were grown at high pressure to fairly large size, representing growth that was within the diffusionlimited regime. The particle-scale habits and aspect ratios are in agreement with measurements by Bailey and Hallett (2004). The habits are qualitatively more elongated than the nearly isometric crystals typically observed in ESEM. The surfaces themselves (Fig. 5) clearly exhibit signatures of mesoscopic roughening that are similar to examples of roughness seen in ESEM-grown crystals. However, for most transported crystals, the crystal edges are more intricate that those observed in ESEM, and portions of surfaces of some transported crystals do appear smooth even at magnification 

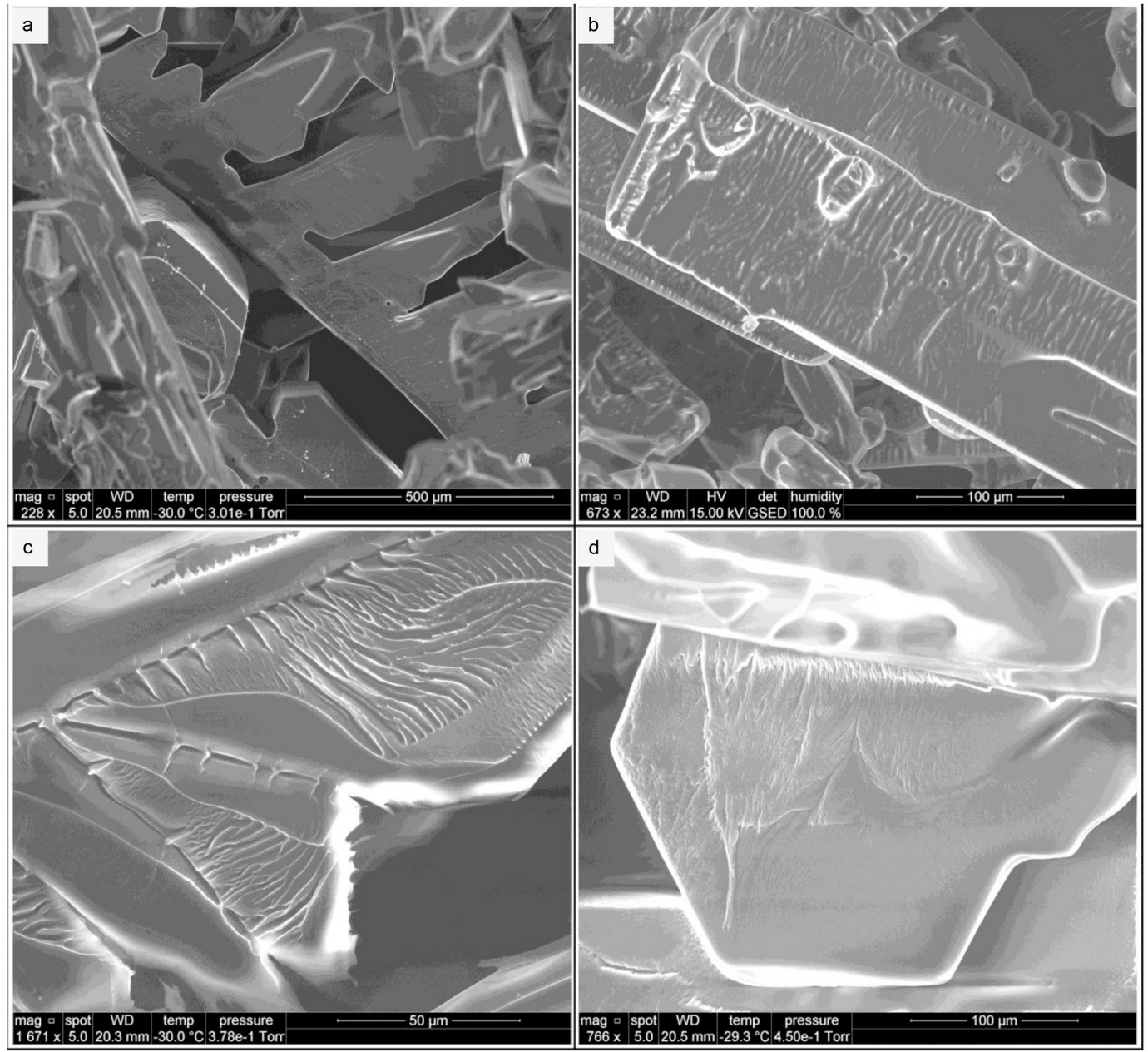

Figure 5. Transported ice crystals, showing portions of four different crystals grown at $-50{ }^{\circ} \mathrm{C}$ in a static diffusion chamber between 100 and $105 \% \mathrm{RH}_{i}$. The crystals were maintained in cryogenic equilibrium during transport into the ESEM for imaging under vapor-matched saturation conditions. Data detail available in Appendix Table A1.

greater than $1000 \times$, a rare observation in our ESEM-grown crystals. While we took efforts to maintain equilibrium conditions between capture and imaging, we still cannot say with certainty that the crystals were not exposed to some variation in $\mathrm{RH}_{i}$ during transport. The transported crystals hint at some significant differences in roughness morphology, but they do provide evidence that crystals grown in air/water mixtures and with minimal support also exhibit mesoscopic roughness with similarity to that observed in ESEM-grown crystals.

\section{Conclusions}

The ESEM images of ice in Sect. 3 confirms the observations on the nature of mesoscopic roughness recently described by several studies (Neshyba et al., 2013, Ulanowski et al., 2014; Pfalgraff et al., 2010, Pedersen et al., 2011; Zimmerman, 2007) and also reveals additional patterns of roughness morphology at high magnification, across a wide range of temperatures, on crystal basal facets, sublimating crystals, and crystals grown in air/water vapor mixtures. Light microscopy has generated highly detailed images of ice crystals (Libbrecht, 2005; Walden et al., 2003), but a combination of working distance constraints, diffraction limits to resolution, and transmitted light illumination have conspired to prevent visible imaging of mesoscopic surface features. We suggest that submicron-scale roughness can also be obscured to detection by ESEM imaging, where the probability of resolving mesoscopic surface topography depends on a combination of factors including the size and depth of the features themselves, the magnification and resolution of the micrograph, the brightness and contrast, and the orientation of the ice crystal with respect to the viewing angle. When brightness and contrast are adjusted to optimal levels, increasing the magnification and resolution serves to create a detailed portrait of ice crystal mesoscopic surfaces which in turn can increase the calculated roughness measure $<r>$. Furthermore, 


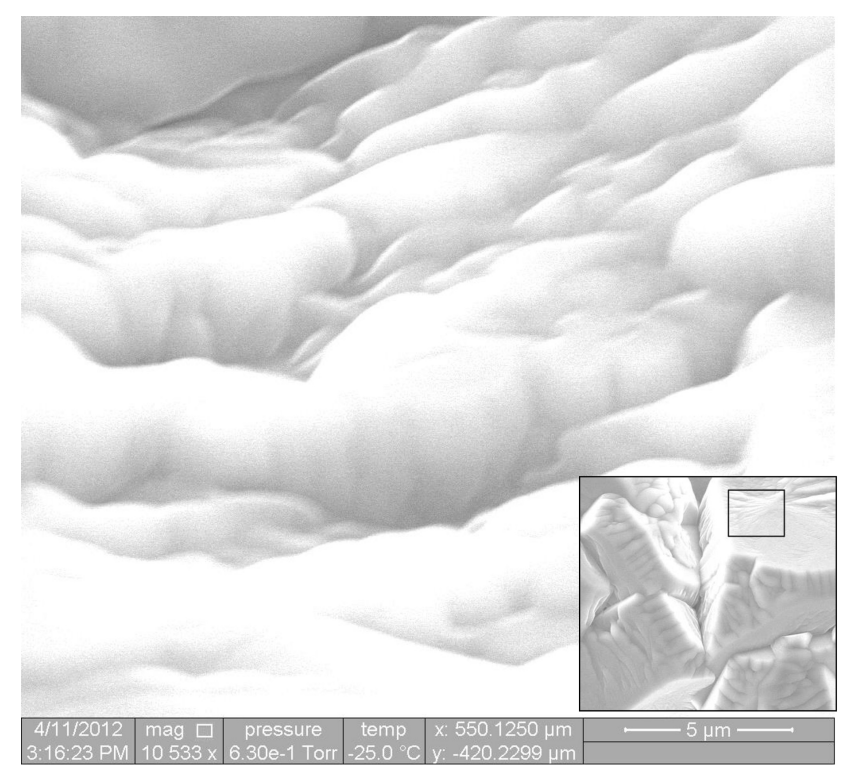

Figure 6. Ice crystals are observed at high magnification, the highest we were able to attain without sacrificing the quality of the image. The inset image $(1903 \times$ magnification) shows the location of the high-magnification zoom, located on the basal facet of a growing crystal, and near to the intersection of the adjoining prism facet with another crystal's basal facet. Data detail available in Appendix Table A1.

high magnification images (near $10000 \times$, as in Fig. 6) depict significant roughness on spatial scales below $200 \mathrm{~nm}$, indicating that for modeling of roughness-induced scattering changes, it is not sufficient to consider light scattering only in the geometric optics regime. Because the ice crystals shown here were grown both inside the pure vapor environment of the ESEM and in external air/vapor mixtures, the ubiquitous presence of mesoscopic roughness indicates that the roughening mechanisms are not caused by the ESEM environment alone and are likely to be significant in atmospheric ice. Despite strong similarity in the subjective appearance of roughness morphologies in crystals grown in diffusionlimited vs. attachment kinetics regimes, there do also appear to be significant differences in overall crystal habit and intricacy of crystal edges, as well as some differences in the patterns of mesoscopic roughness. To increase the utility of these observations, these differences should be investigated further and analyzed quantitatively.
The current microscopy observations appear to be well aligned with a growing body of evidence (Baran 2012; Baum et al., 2011; Ulanowski et al., 2006; Yang et al., 2008; Cole et al., 2013) suggesting that measured scattering from ice crystals fit a rough surface model more successfully than crystals with presumed smooth-faceted surfaces. Several of the satellite studies also point out that while roughened ice particles are strongly indicated by radiative retrievals, these results have not been able to diagnose the physical morphology or scale of the apparent roughness (Cole et al., 2013; Ulanowski et al., 2014) and that further progress will depend on a combination of in situ observations and laboratory measurements, such that realistic representations of surface roughness can be integrated into scattering models.

We believe that these new observations of prevalent surface topography in ice crystals warrant careful consideration in the scattering models that are used for satellite retrievals of cirrus ice microphysics, and in turn, affect the radiative modeling of cirrus clouds in climate models. Furthermore, the ubiquity of a complex mesoscopic landscape on the surface of ice crystals also has potential wide-ranging impacts to theories of charge transfer in thunderstorms, the heterogeneous chemistry of stratospheric ozone, and the sintering of ice crystals in snowpacks and glaciers. We suggest that the next steps should focus on efforts to examine and quantify roughness in crystals transported from cirrus-analog environments and development of a mixed air/vapor capability for ice crystal growth in ESEM. 


\section{Appendix A}

This appendix is intended to provide additional detail regarding thermodynamic conditions and temperature calibration processes that have been used to infer approximate saturation ratios. Appendix Table A1 displays the magnification and thermodynamic data measured in the image panels from Figs. 1-6.

Vapor pressure measurements within the chamber were observed to be repeatable to within approximately $0.4 \mathrm{~Pa}$. Triple-point measurements and ice growth without substrates also showed no discernible systematic error in pressure readings. Reported temperature measurements are made by a thermocouple imbedded in the Peltier cooling sub-stage, several millimeters below the substrate surface. The surface was consistently observed to be several degrees warmer than the sub-stage thermocouple reading. The magnitude of this difference was not constant; rather, it was observed to vary between +0.6 and $+6.5^{\circ} \mathrm{C}$. The magnitude of temperature offset appeared to be increased by the following factors: lower overall temperature, increased substrate thickness, lower substrate thermal conductivity, weaker coolant flow through the Peltier block, and shorter thermal equilibration time. Despite this variation, in each experiment, once a working temperature was established, the vapor pressure could be gradually increased to induce ice nucleation and growth and then gradually decreased until growth ceased and sublimation was first observed - this balance point was set as the equilibrium vapor pressure and used to calculate the inferred surface temperature based on the Murphy and Koop (2005) formulation for saturated vapor pressure over ice: $\ln e_{\mathrm{i}}=9.550426-5723.265 / T+3.53068 \ln (T)$

$-0.00728332 T$

where $e_{\mathrm{i}}$ is the saturation vapor pressure over ice in pascals and $T$ is the ice temperature in kelvins.

Because most experiments involved growth and sublimation induced by vapor pressure adjustments, the variable experimental saturation ratios could be determined relative to the pre-established equilibrium point. In several instances, it was possible to detect slight temperature drift over an hourlong experiment, which could introduce errors of several tenths of a degree in calculated temperatures. Based on these considerations, along with (much smaller) uncertainty in vapor pressure, the calibrated surface temperatures are deemed to be valid $\pm 0.3^{\circ} \mathrm{C}$ and ice saturation ratio calculations to have approximately $\pm 4 \%$ confidence. Introduction of additional thermometry points will be undertaken in future work in order to reduce uncertainty in surface temperatures and saturation ratio, enabling quantitative modeling of growth and sublimation rates. 
Table A1. Magnification, temperature, vapor pressure, and calculated saturation ratios for images in figures.

\begin{tabular}{|c|c|c|c|c|c|}
\hline Panel & Magnification & $\begin{array}{c}\text { Vapor } \\
\text { Pressure }(\mathrm{Pa}) \\
\{ \pm 0.5 \mathrm{~Pa}\}\end{array}$ & $\begin{array}{l}\text { Sub-stage } \\
\text { Temp. }\left({ }^{\circ} \mathrm{C}\right) \\
\left\{ \pm 0.1^{\circ} \mathrm{C}\right\}\end{array}$ & $\begin{array}{c}\text { Calibrated surface } \\
\text { Temp. }\left({ }^{\circ} \mathrm{C}\right) \\
\left\{ \pm 0.3^{\circ} \mathrm{C}\right\}\end{array}$ & $\begin{array}{c}\text { Ice Saturation } \\
\text { Ratio } \\
\{ \pm 4 \%\}\end{array}$ \\
\hline \multicolumn{6}{|c|}{ Figure 1} \\
\hline $\mathrm{a}$ & 350 & 73.3 & -25.0 & -24.0 & 1.05 \\
\hline $\mathrm{b}$ & 694 & 73.3 & -24.0 & 1.05 & \\
\hline $\mathrm{c}$ & 1061 & 75.2 & -25.0 & -23.9 & 1.06 \\
\hline d & 834 & $\mathrm{n} / \mathrm{a}$ & $\mathrm{n} / \mathrm{a}$ & $\mathrm{n} / \mathrm{a}$ & $\mathrm{n} / \mathrm{a}$ \\
\hline $\mathrm{e}$ & 1559 & 29.1 & -37.6 & -33.8 & 1.14 \\
\hline$f$ & 2249 & 25.3 & -39.2 & -35.2 & 1.13 \\
\hline g & 669 & 25.3 & -40.6 & -35.5 & 1.20 \\
\hline $\mathrm{h}$ & 1031 & 22.9 & -41.0 & -36.0 & 1.14 \\
\hline $\mathrm{i}$ & 2453 & 22.9 & -41.0 & -36.0 & 1.14 \\
\hline \multicolumn{6}{|c|}{ Figure 2} \\
\hline $\mathrm{a}$ & 762 & 93.6 & -25.0 & -22.0 & 1.00 \\
\hline $\mathrm{b}$ & 2155 & 93.2 & -25.0 & -22.0 & 1.00 \\
\hline $\mathrm{c}$ & 3625 & 93.6 & -25.0 & -22.0 & 0.99 \\
\hline d & 3625 & 93.6 & -25.0 & -22.0 & 1.00 \\
\hline \multicolumn{6}{|c|}{ Figure 3} \\
\hline $\mathrm{a}$ & 2858 & 29.5 & -37.5 & -32.6 & 1.02 \\
\hline $\mathrm{b}$ & 2858 & 29.5 & -37.8 & -32.9 & 1.05 \\
\hline $\mathrm{c}$ & 2858 & 29.5 & -37.8 & -32.9 & 1.05 \\
\hline d & 2858 & 29.1 & -37.8 & -32.9 & 1.04 \\
\hline $\mathrm{e}$ & 2858 & 29.5 & -37.8 & -32.9 & 1.05 \\
\hline$f$ & 2858 & 29.5 & -37.8 & -32.9 & 1.05 \\
\hline \multicolumn{6}{|c|}{ Figure 4} \\
\hline $\mathrm{a}$ & 519 & $\mathrm{n} / \mathrm{a}$ & $\mathrm{n} / \mathrm{a}$ & $\mathrm{n} / \mathrm{a}$ & $\mathrm{n} / \mathrm{a}$ \\
\hline b & 927 & 29.1 & -36.5 & -32.0 & 0.94 \\
\hline c & 669 & 25.3 & -39.0 & -33.5 & 0.96 \\
\hline $\mathrm{d}$ & 1532 & 27.6 & -40.0 & -33.0 & 0.99 \\
\hline \multicolumn{6}{|c|}{ Figure 5} \\
\hline $\mathrm{a}$ & 228 & 40.1 & -30.0 & -29.4 & 1.00 \\
\hline b & 673 & $\mathrm{n} / \mathrm{a}$ & $\mathrm{n} / \mathrm{a}$ & $\mathrm{n} / \mathrm{a}$ & $\mathrm{n} / \mathrm{a}$ \\
\hline c & 1671 & 50.4 & -30.0 & -27.3 & 1.00 \\
\hline $\mathrm{d}$ & 766 & 60.0 & -29.3 & -25.5 & 1.00 \\
\hline \multicolumn{6}{|c|}{ Figure 6} \\
\hline main & 10533 & 84.0 & -25.0 & -22.4 & 1.05 \\
\hline
\end{tabular}




\section{The Supplement related to this article is available online at doi:10.5194/acp-14-12357-2014-supplement.}

Acknowledgements. The authors thank J. Poirier at the Princeton Image and Analysis Center for essential technical assistance with ESEM imaging. Research support was generously provided by the Research Corporation Cottrell College Science Award 19914, NASA EPOESS grant \#10-0047, and The College of New Jersey.

Edited by: A. Laskin

\section{References}

Bailey, M. and Hallett, J.: Growth Rates and Habits of Ice Crystals between $-20^{\circ}$ and $-70^{\circ} \mathrm{C}$, J. Atmos. Sci., 61, 514-554, 2004.

Baran, A. J. and Labonnote, L.: On the reflection and polarization properties of ice clouds, J. Quant. Spectrosc. Ra., 100, 41-54, 2006.

Baran, A. J.: From the single-scattering properties of ice crystals to climate prediction: a way forward, Atmos. Res., 112, 45-69, 2012.

Baum, B. A., Yang, P., Hu, Y., and Feng, Q.: The impact of ice particle roughness on the scattering phase matrix, J. Quant. Spectrosc. Ra., 111, 2534-2549, 2010.

Baum, B. A., Yang, P., Heymsfield, A. J., Schmitt, C. G., Xie, Y., Bansemer, A., Hu, Y., J., and Zhang, Z.: Improvements in shortwave scattering and absorption models for the remote sensing of ice clouds, J. Appl. Meteorol. Clim., 50, 1037-1056, 2011.

Bennett, H. E. and Porteus, J. O.: Relation between surface roughness and specular reflectance at normal incidence, J. Opt. Soc. Am., 51, 123-129, 1961.

Blackford, J. R.: Sintering and microstructure of ice: a review, J. Phys. D Appl. Phys., 40, R355, doi:10.1088/00223727/40/21/R02, 2007.

Bony, S., Colman, R., Kattsov, V. M., Allan, R. P., Bretherton, C. S., Dufresne, J.-L., Hall, A., Hallegatte, S., Holland, M. M., Ingram, W., Randall, D. A., Soden, B. J., Tselioudis, G., and Webb, M.: How well do we understand and evaluate climate change feedback processes?, J. Climate, 19, 3445-3482, 2006.

Bryant, G. W., Hallett, J., and Mason, B. J.: The epitaxial growth of ice on single-crystalline substrates, J. Phys. Chem. Solids, 12, 189-195, 1960.

Burkhardt, U. and Kärcher, B.: Global radiative forcing from contrail cirrus, Nature Climate Change, 1, 54-58, 2011.

Chepfer, H., Goloub, P., Riedi, J., de Haan, J. F., and Hovenier, J. W.: Ice crystal shapes in cirrus clouds derived from POLDER-1/ADEOS-1, J. Geophys. Res., 106, 7955-7966, doi:10.1029/2000JD900285, 2001.

Cole, B., Yang, P., Baum, B. A., Riedi, J., Labonnote, L., Thieuleux, F., and Platnick, S.: Comparison of PARASOL observations with polarized reflectances simulated using different ice habit mixtures, J. Appl. Meteor. Clim., 52, 186-196, 2013.

Cole, B., Yang, P., Baum, B. A., Riedi, J., and Labonnote, L.: Ice particle habit and surface roughness derived from PARASOL polarization measurements, Atmos. Chem. Phys., 14, 3739-3750, doi:10.5194/acp-14-3739-2014, 2014.
Connolly, P., Flynn, M., Ulanowski, Z., Chourlatan, T. W., Gallagher, M., and Bower, K. N.: Calibration of the Cloud Particle Imager Probes Using Calibration Beads and Ice Crystal Analogs: The Depth of Field, J. Atmos. Oceanic Tech , 24, 1860-1879, 2007.

Cotton, R., Osborne, S. Ulanowski, Z., Hirst, E., Kaye, P. H., and Greenaway, R. S.: The ability of the small ice detector, SID-2 to characterize cloud particle and aerosol morphologies obtained during flights of the FAAM BAe-146 research aircraft, J. Atmos. Ocean. Tech., 27, 290-303, 2010.

Dash, J. G., Mason, B. L., and Wettlaufer, J. S.: Theory of charge and mass transfer in ice-ice collisions, J. Geophys. Res., 106, 20395-20402, 2001.

Furukawa, Y., Yamamoto, M., and Kuroda, T. Ellipsometric study of the transition layer on the surface of an ice crystal, J. Cryst. Growth, 82, 665-677, 1987.

Garrett, T. J., Gerber, H., Baumgardner, D. G., Twohy, C. H., and Weinstock, E. M.: Small, highly reflective ice crystals in low-latitude cirrus, Geophys. Res. Lett., 30, 2132 , doi:10.1029/2003GL018153, 2003.

Gierens, K. M., Monier, M., and Gayet, J.-F.: The deposition coefficient and its role for cirrus clouds, J. Geophys. Res., 108, 4059-4063, 2003.

Goodman, J., Toon, O. B., Pueschel, R. F., Snetsinger, K. G., and Verma, S.: Antarctic stratospheric ice crystals, J. of Geophys Res.-Atmos. 94, 16449-16457, 1989.

Harrington, J. Y., Lamb, D., and Carver, R.: Parameterization of surface kinetic effects for bulk microphysical models: Influences on simulated cirrus dynamics and structure, J. Geophys. Res. 114, D06212, doi:10.1029/2008JD011050, 2009.

Heymsfield, A. J., Schmitt, C., Bansemer, A, Van Zadelhoff, G. J., McGill, M. J., Twohy, C., and Baumgardner, D.: Effective radius of ice cloud particle populations derived from aircraft probes, J. Atmos. Ocean. Tech., 23, 361-380, 2006.

IPCC, 2013 Climate Change 2013: The Physical Science Basis. Contribution of Working Group I to the Fifth Assessment Report of the Intergovernmental Panel on Climate Change, Cambridge University Press, Cambridge, 2013.

Jensen, E. J., Lawson, P., Baker, B., Pilson, B., Mo, Q., Heymsfield, A. J., Bansemer, A., Bui, T. P., McGill, M., Hlavka, D., Heymsfield, G., Platnick, S., Arnold, G. T., and Tanelli, S.: On the importance of small ice crystals in tropical anvil cirrus, Atmos. Chem. Phys., 9, 5519-5537, doi:10.5194/acp-9-5519-2009, 2009.

Kahnert, M., Sandvik, A. D., Biryulina, M., Stamnes, J. J., and Stamnes, K.: Impact of ice particle shape on short-wave radiative forcing: a case study for an arctic ice cloud, J. Quant. Spectrosc. Ra., 109, 1196-1218, 2008.

Krämer, M., Schiller, C., Afchine, A., Bauer, R., Gensch, I., Mangold, A., Schlicht, S., Spelten, N., Sitnikov, N., Borrmann, S., de Reus, M., and Spichtinger, P.: Ice supersaturations and cirrus cloud crystal numbers, Atmos. Chem. Phys., 9, 3505-3522, doi:10.5194/acp-9-3505-2009, 2009.

Kuhs, W. F., Sippel, C., Falenty, A., and Hansen, T. C.: Extent and relevance of stacking disorder in "ice Ic", P Natl. Acad. Sci. USA, 109, 21259-21264, 2012.

Kuroiwa, D.: Surface topography of etched ice crystals observed by a scanning electron microscope, J. Glaciol., 475-483, 1969. 
Kuroda, T. and Lacmann, R.: Growth kinetics of ice from the vapour phase and its growth forms, J. Cryst. Growth, 56, 189-205, 1982.

Lamb, D. and Hobbs, P. V.: Growth rates and habits of ice crystals grown from the vapor phase, J. Atmos. Sci., 28, 1506-1509, 1971.

Lamb, D.: Crystal growth: 2-D or not 2-D?, in: Proc. of 13th Inter. Conf. on Clouds and Precip., Reno, NV, 1221-1224, 14-18 August, 2000.

Libbrecht, K.: The physics of snow crystals, Rep. Prog. Phys., 68, 855-895, doi:10.1088/0034-4885/68/4/R03, 2005.

Magee, N., Moyle, A. M., and Lamb, D.: Experimental determination of the deposition coefficient of small cirrus-like ice crystals near $-50{ }^{\circ} \mathrm{C}$, Geophys. Res. Lett., 33, L17813, doi:10.1029/2006GL026665, 2006.

Malkin, T. L., Murray, B. J., Brukhno, A. V., Anwar, J., and Salzmann, C. G.: Structure of ice crystallized from supercooled water, P. Natl. Acad. Sci. USA, 109, 1041-1045, doi:10.1073/pnas.1113059109, 2012.

Mauno, P., McFarquhar, G. M., Räisänen, P., Kahnert, M., Timlin, M. S., and Nousiainen, T.: The influence of observed cirrus microphysical properties on shortwave radiation: a case study over Oklahoma, J. Geophys. Res., 116, D22208, doi:10.1029/2011JD016058, 2011.

McFarquhar, G. M., Um, J., Freer, M., Baumgardner, D., Kok, G. L., and Mace, G.: Importance of small ice crystals to cirrus properties: observations from the Tropical Warm Pool International Cloud Experiment, TWP-ICE, Geophys. Res. Lett., 34, L13803, doi:10.1029/2007GL029865, 2007.

McNeill, V. F., Geiger, F. M., Loerting, T., Trout, B. L., Molina, L. T., and Molina, M. J.: Interaction of hydrogen chloride with ice surfaces: the effects of grain size, surface roughness, and surface disorder, J. Phys. Chem. A, 111, 6274-6284, 2007.

Mitchell, D. L., Rasch, P., Ivanova, D., McFarquhar, G., and Nousiaine, T.: Impact of small ice crystal assumptions on ice sedimentation rates in cirrus clouds and GCM simulation, Geophys. Res. Lett., 35, L09806, doi:10.1029/2008GL033552, 2008.

Murray, B. J. and Bertram, A. K.: Formation and stability of cubic ice in water droplets, Phys. Chem. Chem. Phys., 8, 186-192, 2006.

Nelson, J. and Knight, C.: Snow crystal habit changes explained by layer nucleation, J. Atmos. Sci., 55, 1452-1464, 1998.

Neshyba, S. P., Lowen, B., Benning, M., Lawson, A., and Rowe, P. M.: Roughness metrics of prismatic facets of ice, J. Geophys. Res.- Atmos., 3309-3318, doi:10.1002/jgrd.50357, 2013.

Pedersen, C., Mihranyan, A., and Stromme, M.: Surface transition on ice induced by the formation of a grain boundary, PLoS one, 6, e24373, doi:10.1371/journal.pone.0024373, 2011.

Peter, T., Marcolli, C., Spichtinger, P., Corti, T., Baker, M. B., and Koop, T.: When dry air is too humid, Science, 314, 1399-1402, 2006.

Pfalzgraff, W. C., Hulscher, R. M., and Neshyba, S. P.: Scanning electron microscopy and molecular dynamics of surfaces of growing and ablating hexagonal ice crystals, Atmos. Chem. Phys., 10, 2927-2935, doi:10.5194/acp-10-2927-2010, 2010.

Saunders, C. P. R.: Thunderstorm electrification laboratory experiments and charging mechanisms, J. Geophys. Res., 99, 10773-10779, 1994.
Sazaki, G., Zepeda, S., Nakatsubo, S., Yokoyama, E., and Furukawa, Y.: Elementary steps at the surface of ice crystals visualized by advanced optical microscopy, P. Natl. Acad. Sci. USA, 107, 19702-19707, 2010.

Schaefer, V. J.: A method for making snowflake replicas, Science, 93, 239-240, 1941.

Schnaiter, M., Kaye, P. H., Hirst, E., Ulanowski, Z., and Wagner, R.: Exploring the surface roughness of small ice crystals by measuring high resolution angular scattering patterns, AAPP, 89, C1V89S1P084, doi:10.1478/C1V89S1P084, 2011.

Shcherbakov, V., Gayet, J. F., Backer, B., and Lawson, P.: Light scattering by single natural ice crystals, Am. Meteorol. Soc., 63, 1513-1525, 2006.

Sun, W., Hu, Y., Lin, B., Liu, Z., and Videen, G.: The impact of ice cloud particle microphysics on the uncertainty of ice water content retrievals, J. Quant. Spectrosc. Ra., 112, 189-196, 2011.

Takahashi, T. and Fukuta, N.: Ice crystal replication with common plastic solutions, J. Atmos. Ocean. Tech., 5, 129-135, 1988.

Truby, F. K.: Hexagonal microstructure of ice crystals grown from the melt, J. Appl. Phys., 26, 1416-1420, 1955.

Ulanowski, Z., Hesse, H., Kaye, P. H., Baran, A. J.: Light scattering by complex ice-analogue crystals, J. Quant. Spectrosc. Ra., 100, 382-392, doi:10.1016/j.jqsrt.2005.11.052, 2006.

Ulanowski, Z., Hirst, E., Kaye, P. H., and Greenaway, R.: Retrieving the size of particles with rough and complex surfaces from twodimensional scattering patterns, J. Quant. Spectrosc. Ra., 113, 2457-2464, doi:10.1016/j.jqsrt.2012.06.019, 2012.

Ulanowski, Z., Kaye, P. H., Hirst, E., and Greenaway, R. S.: Light scattering by ice particles in the Earth's atmosphere and related laboratory measurements, in: Procs. 12th Int. Conf. on Electromagnetic and Light Scattering: ELS'XII, 28 June-2 July 2010, Helsinki, Finland, 294-297, 2010.

Ulanowski, Z., Kaye, P. H., Hirst, E., Greenaway, R. S., Cotton, R. J., Hesse, E., and Collier, C. T.: Incidence of rough and irregular atmospheric ice particles from Small Ice Detector 3 measurements, Atmos. Chem. Phys., 14, 1649-1662, doi:10.5194/acp14-1649-2014, 2014.

Um, J. and McFarquhar, G. M.: Dependence of the single-scattering properties of small ice crystals on idealized shape models, Atmos. Chem. Phys., 11, 3159-3171, doi:10.5194/acp-11-31592011, 2011.

Walden, V. P., Warren, S. G., and Tuttle, E.: Atmospheric ice crystals over the antarctic plateau in winter, Am. Meteorol. Soc., 42, 1391-1405, 2003.

Wergin, W. P., Rango, A., and Erbe, E. F.: Observations of snow crystals using low-temperature scanning electron microscopy, Scanning, 17, 41-49, 1995.

Yang, H., Dobbie, S., Herbert, R., Connolly, P., Gallagher, M., Ghosh, S., Al-Jumur, S. M. R. K., and Clayton, J.: The effect of observed vertical structure, habits, and size distributions on the solar radiative properties and cloud evolution of cirrus clouds, Q. J. Roy. Meteor. Soc., 138, 1221-1232, 2012.

Yang, P. and Liou, K. N.: Single-scattering properties of complex ice crystals in terrestrial atmosphere, Contr. Atmos. Phys., 71, 223-248, 1998.

Yang, P., Hong, G., Kattawar, G., Minnis, P., and Hu, Y.: Uncertainties associated with the surface texture of ice particles in satellitebased retrieval of cirrus clouds: Part II - Effect of particle surface 
roughness on retrieved cloud optical thickness and effective particle size, IEEE T. Geosci. Remote, 46, 1948-1957, 2008.

Yang, P., Bi, L., Baum, B. A., Liou, K. N., Kattawar, G. W., Mishchenko, M. I., and Cole, B.: Spectrally consistent scattering, absorption, and polarization properties of atmospheric ice crystals at wavelengths from 0.2 to $100 \mu \mathrm{m}$, J. Atmos. Sci., 70, 330-347, 2013.

Yi, B., Yang, P., Baum, B. A., L'Ecuyer, T., Oreopoulos, L., Mlawer, E. J., Heymsfield, A. J., and Liou, K. N.: Influence of ice particle surface roughening on the global cloud radiative effect, J. Atmos. Sci., 70, 2794-2807, doi:10.1175/JAS-D-13020.1, 2013.
Zimmermann, F., Ebert, M., Worringen, A., Schutz, L., and Weinbruch, S.: Environmental scanning electron microscopy, ESEM as a new technique to determine ice nucleation capability of individual atmospheric particles, Atmos. Environ., 41, 8219-8227, 2007. 